\title{
Saúde e espaço urbano: a promoção de cidades mais saudáveis e sustentáveis
}

Health and urban space: promoting healthier and sustainable cities

Salud y espacio urbano: la promoción de ciudades más sanas y sostenibles

\section{Douglas Gallo}

Professor Mestre, IFSP, Brasil Doutorando em Urbanismo, PROURB/FAU/UFRJ, Brasil

douglas.luciano@yahoo.com.br

Eliane Ribeiro de Almeida da Silva Bessa

Professora Doutora, PROURB/FAU/UFRJUFS, Brasil elianesilbessa@gmail.com 

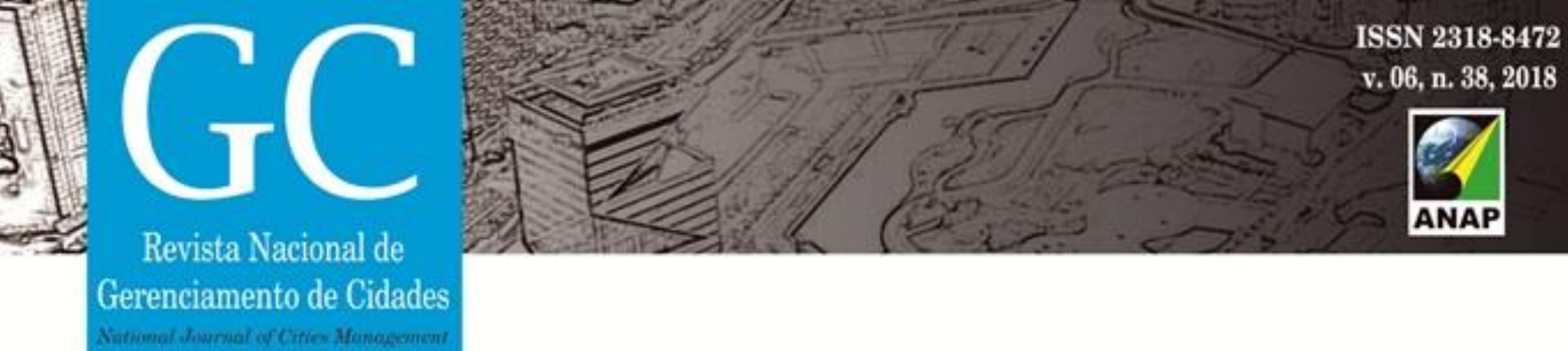

RESUMO

Este artigo tem por objetivo investigar como o espaço urbano pode influenciar na qualidade de vida urbana e seu papel na promoção de uma cidade mais saudável e sustentável. Foi realizado levantamento bibliográfico com o intuito de construir uma discussão crítica das relações entre saúde e urbanismo, procurando compreender suas interconexões, potencialidades e dificuldades. Ao adotar a qualidade de vida urbana e o bem-estar como parâmetros para o planejamento e gestão urbana, as políticas públicas buscam integrar os esforços e agentes sociais para a melhoria das condições de vida da população. Somente com ações integrais e intersetoriais pode-se promover cidades mais saudáveis e sustentáveis, com engajamento social e mais equidade. 0 movimento das cidades saudáveis busca exatamente pensar a saúde urbana como recurso para a vida e felicidade de seus moradores.

PALAVRAS-CHAVE: Saúde urbana. Cidades saudáveis. Sustentabilidade.

\section{ABSTRACT}

This study aimed to investigate how urban space can influence the urban quality of life and how can promote a healthy and sustainable city. A bibliographic research was carried out in order to construct a critical discussion of the relations between health and urban space, search their interconnections, potentialities and difficulties. By adopting urban quality of life and well-being as parameters for urban planning and management, public policies seek to integrate efforts and social agents can one promote healthier and sustainable cities with social engagement and more equity. The movement of healthy cities precisely seeks to think of urban health as a resource for the life and happiness of its residents.

KEYWORDS: Urban health. Healthy city. Sustainability.

\section{RESUMEN}

El propósito de este ensayo es investigar cómo el espacio urbano puede influir en la calidad de vida urbana y su papel en la promoción de una ciudad más saludable y sostenible. Se realizó un levantamiento bibliográfico con el propósito de construir una discusión crítica de las relaciones entre salud y urbanismo, buscando comprender sus interconexiones, potencialidades y dificultades. Al adoptar la calidad de vida urbana y el bienestar como parámetros para la planificación y gestión urbana, las políticas públicas buscan integrar los esfuerzos y agentes sociales para la mejora de las condiciones de vida de la población. Sólo con acciones integrales e intersectoriales se pueden promover ciudades más saludables y sostenibles, con compromiso social y más equidad. El movimiento de las ciudades saludables busca exactamente pensar la salud urbana como recurso para la vida y la felicidad de sus habitantes.

PALABRAS CLAVE: Salud urbana. Ciudad saludable. Sostenibilidad. 


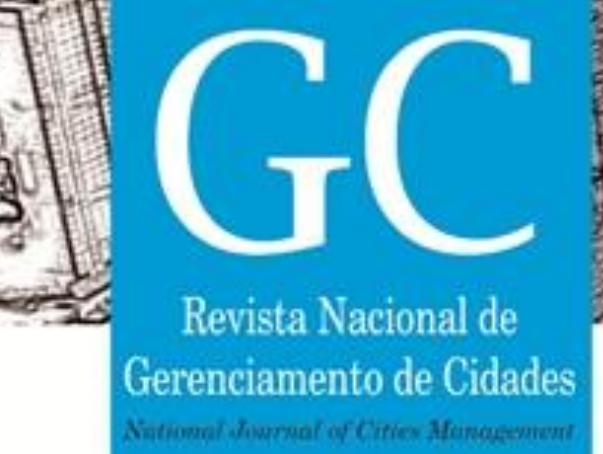

\section{INTRODUÇÃO}

O mundo contemporâneo é marcado pelo urbano, os novos modos de produzir cultura, subjetividades e mesmo as cidades, se desenvolvem tendo em vista as questões urbanas não solucionadas pelo paradigma da modernidade. As transformações decorrentes das novas tecnologias e pela mudança na produção e circulação simbólica estão associadas a esta nova sociedade dispersa numa trama urbana nacional e internacional, onde a oferta simbólica é continuamente renovada e homogeneizada pela subjetividade capitalista (GUATTARI e ROLNIK, 2000).

Encontramo-nos numa sociedade urbana, o processo de urbanização nos trouxe a uma realidade nova, a forma de viver é urbana, mesmo no campo, na contemporaneidade o homem é um ser urbano. Este urbano, segundo Castells (1983: 17), é "uma forma especial de ocupação do espaço por uma população", fruto de forte concentração e alta densidade, com marcante diferenciação social e funcional.

Para Lefebvre $(1999,2001)$, a industrialização, característica da sociedade moderna, induziu à urbanização e à problemática urbana, porém a urbanização passou de induzida a indutora. Este termo 'sociedade urbana' responde a uma questão teórica, mas também prática, levando ao pensamento urbanístico e ao planejamento urbano aplicado.

A urbanização contemporânea se entrelaça com a serialização e o anonimato produzido pelos meios de comunicação imaterial (dos meios de massa à telemática) modificando os vínculos entre público e privado, num processo constante de hibridação cultural (CANCLINI, 2013).

A crise urbana, assim, advém da crescente incapacidade que a organização social capitalista tem de assegurar a produção, distribuição e gestão dos meios de consumo coletivos, como moradia, educação, transporte, saúde, áreas verdes etc. O consumo destes equipamentos coletivos se dá na estrutura urbana e como não são suficientemente rentáveis para serem produzidos pelo capital, torna-se necessário que os serviços públicos assumam sua gestão (CASTELLS, 1980).

O esvaziamento do espaço público tem como consequência, e fonte geradora, a colonização da esfera pública pela privada, configurando um mundo fragmentado e mercantilizado (SILVA, 2011). O espaço urbano, local do encontro com o estranho, tem sido relegado à gente perigosa, enquanto o inocente precisa deixar a segurança de seus carros para adentrar neste espaço, que deveria ser rico de oportunidades e encontros sociais. 
Com o aumento da população nas cidades ocorreu um agravamento das iniquidades sociais e uma maior dificuldade de acesso aos serviços essenciais, com consequente diminuição do bem-estar urbano. A saúde urbana sofre diversas influências: condições físicas da residência e trabalho, meio ambiente natural, social e econômico, assim como o acesso e a qualidade dos serviços públicos. Segundo Machado (2007), um meio urbano adverso aumenta os riscos de saúde da população, de forma especial dos mais vulneráveis (idosos, crianças e jovens).

Ao falarmos de saúde urbana, alguns desafios devem ser considerados: déficit habitacional, precariedade do saneamento básico e coleta de lixo, a área da saúde e a mobilidade urbana (AKEMAN, DUHL e BOGUS, 2006). Uma concepção sociecológica do urbano deve compreender toda a complexidade da questão, numa visão holística e integral.

Tendo em vista esta realidade, como o Estado e as políticas públicas podem promover a saúde urbana e um espaço saudável? Como a qualidade de vida urbana pode ser influenciada pelas políticas focadas no bem-estar e no paradigma da promoção da saúde? Até que ponto as políticas desenvolvidas são efetivas neste aspecto, ou atuam mais como marketing urbano dentro de um mercado global?

O presente artigo pretende contribuir para a discussão das relações entre a saúde e o espaço urbano, visto este como possibilidade para a promoção de uma cidade mais saudável e sustentável. O objetivo foi investigar como o espaço urbano pode influenciar na qualidade de vida urbana e seu papel na promoção de uma cidade mais sustentável e saudável. Para tanto foram realizados levantamentos bibliográficos e documentais, com análise crítica buscando responder a uma lacuna histórica nos estudos urbanos.

\section{UM NOVO PARADIGMA EM SAÚDE}

O termo paradigma designa qualquer tipo de conhecimento humano com referência a práticas sociais, em um sentido técnico constitui-se num instrumento de abstração, uma ferramenta de auxílio ao pensamento científico. Num sentido mais amplo relaciona-se a uma visão de mundo, implicando num conjunto de generalizações simbólicas aceitas por determinada comunidade científica, sendo que no campo da saúde está relacionado a movimentos ideológicos, conjunto de noções, pressupostos e crenças. Estes, ao serem compartilhados pelos sujeitos sociais, servem de referencial para a ação (PAIM e ALMEIDA FILHO, 2000). Podemos considerar como principais 
paradigmas de saúde o Flexneriano, o da Medicina Preventiva, o da Saúde Comunitária e o da Promoção da Saúde ou Saúde Coletiva.

No início do século XX, foi publicado o Relatório Flexner, desencadeando uma profunda reavaliação nas bases científicas da medicina, reforçando a separação entre individual e coletivo, privado e público, biológico e social, curativo e preventivo. Já a Medicina Preventiva emergiu de um campo formado pela higiene, pela discussão dos altos custos da atenção médica e pela redefinição das responsabilidades médicas, surgida no interior das discussões na educação médica. A proposta da Saúde Comunitária recuperou o discurso preventivista, porém enfatizava as ciências sociais aplicadas aos problemas de saúde, integrando as equipes da saúde comunitárias aos agentes e forças sociais locais (AROUCA, 2003; PAIM e ALMEIDA FILHA, 2000).

Segundo Mendes (1996), um novo paradigma na saúde foi sendo desenvolvido em oposição ao modelo flexneriano, cuja visão negativa da saúde se desenvolveu como ausência da doença. Este novo paradigma considera a saúde em sua positividade e como processo social com fatores que lhe são determinantes. Esta produção social da saúde implica considerar que numa determinada sociedade, num determinado momento, existem ou inexistem capacidades de gerar e acumular saúde.

Esta redefinição de paradigma, do modelo flexneriano para o da promoção social da saúde, com enfoque na promoção da saúde e qualidade de vida, ultrapassa o próprio termo e pretende uma reorientação de todo processo assistencial (FERREIRA, 2010). O conceito de promoção de saúde reforça uma ação ambiental e política. Entende-se a promoção como:

[...] processo de capacitação da comunidade para atuar na melhoria de sua qualidade de vida e saúde, incluindo uma maior participação no controle deste processo. Para atingir um estado de completo bem-estar físico, mental e social os indivíduos e grupos devem saber identificar aspirações, satisfazer necessidades e modificar favoravelmente o meio ambiente. A saúde deve ser vista como um recurso para vida, e não como objetivos de viver. (CARTA DE OTAWA, 1986: s/p).

\section{PROMOÇÃO DA SAÚDE, QUESTÃO DE POLÍTICA PÚBLICA}

Existem duas abordagens principais do conceito de promoção da saúde: uma dirigida ao comportamento individual, focando nos estilos de vida, ambientes e territórios; e outra focada no entendimento de saúde como qualidade de vida (BUSS, 2000). A própria ideia de promoção da saúde se traduz numa abordagem intersetorial, focada no desenvolvimento sustentável e na adoção de políticas públicas saudáveis (CZERESNIA e FREITAS, 2009). 
Para Lefevre e Lefevre (2004), a promoção da saúde deve deslocar seu objeto do corpo para os espaços sociais. As cidades precisam resolver um duplo problema, atender às demandas locais e ao mesmo tempo tornar-se competitivas num mercado global. Existe uma forte confluência entre os conceitos de promoção da saúde, desenvolvimento sustentável, direito à cidade e à moradia, cooperativismo, dentre outros. A abordagem sendo sempre determinada por fatores internos e externos à área específica, intersetorial e voltada ao enfrentamento dos problemas identificados, com forte apelo à proteção da saúde humana e fundamentada em políticas públicas sustentáveis. No desenvolvimento sustentável o ser humano é o protagonista, e ao ter um aumento na perspectiva de vida saudável e com qualidade, amplia sua participação na comunidade e nas definições de questões coletivas (BUSS, 2009; SIMÕES, 2007).

As políticas públicas são ações nascidas num determinado contexto social, que ao passarem pela instância estatal, materializam-se em investimentos ou regulamentações administrativas, para atuarem como intervenções em determinadas realidades sociais. São resultado do jogo de forças entre grupos políticos e econômicos, classes sociais e sociedade civil organizada. Desta forma, as políticas públicas não são definidas tendo como parâmetro unicamente o bem comum, nem tão pouco os interesses específicos de determinadas classes, mas desenham-se na complexidade da relação entre os diferentes agentes, que as elaboram e as operacionalizam (BONETI, 2007).

A promoção da saúde deve ultrapassar o cuidado à saúde, redefinindo o lugar da saúde na agenda das decisões políticas, permeando todos os níveis e setores da gestão pública. Desta forma, as políticas públicas são responsabilizadas pelas decisões sobre a saúde e qualidade de vida da população, combinando abordagens diversas e complementares (BONATTO, 2012). Esta característica intrínseca a área, evidencia a importante relação entre urbanismo, planejamento urbano e saúde, caracterizando o paradigma da promoção como necessário para o pensamento urbano.

A relação entre saúde e urbanização é milenar, com foco no bem-estar dos cidadãos e o planejamento urbano, tendo a salubridade e questões habitacionais como centro dos problemas sociais. A aplicação dos princípios da higiene no ambiente urbano foi o embrião do planejamento das cidades (GASPAR, 2007). 


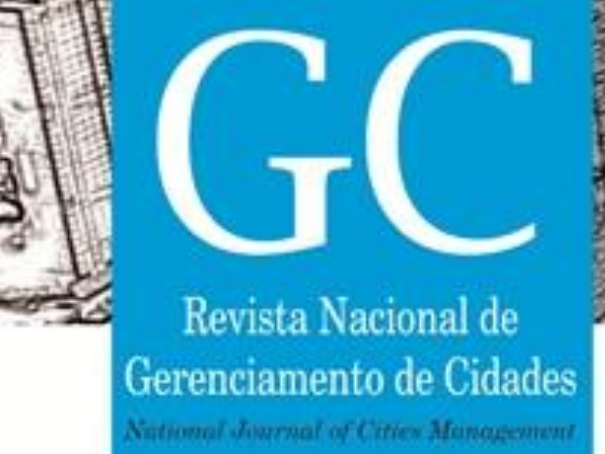

\section{ESPAÇO URBANO E SAÚDE, UMA RELAÇÃO FUNDAMENTAL}

Para compreendermos a relação entre saúde e urbano devemos olhar para o desenvolvimento histórico das cidades. Desde a passagem do nomadismo para o sedentarismo o conhecimento produzido sobre o processo saúde-doença é influenciado, para não dizer determinado, pela visão integrada entre fenômenos e lugares.

Na Antiguidade, Hipócrates (460-370 a.C.) já relacionava, como fatores importantes para a localização de uma cidade, aspectos ambientais e climáticos como influenciadores nas doenças. Sua obra permaneceu como fundamental no ensino da medicina até finais do século XIX (SIMÕES, 2007). Nas cidades gregas e romanas o abastecimento de água e esgotamento sanitário já se faziam presentes, como princípios higienistas.

No período medieval as ações do governo voltaram-se para o espírito, abandonando o corpo e seu cuidado, com isso, pouco foi desenvolvido do saber higienista. A não observância desses saberes clássicos levou a grandes desastres nas cidades medievais. Sendo este conhecimento retomado com o renascimento das cidades europeias. 0 domínio dos conhecimentos hidráulicos (Galileu, Leonardo e Torricelli) levou à busca por cidades mais saudáveis (WESTPHAL, 2006; GASPAR, 2007).

No contexto da Revolução Industrial o ambiente urbano estava precarizado e insalubre, evidenciando a necessidade de saneamento e higiene pública. A reforma da cidade industrial no século XIX buscou trazer ar puro, água fresca e espaços verdes e ensolarados para as cidades, caracterizando um bom urbanismo (MUMFORD, 1998). O avanço do conhecimento científico e da medicina levaram a criação da utopia da Hygeia, ou "cidade da saúde", publicada em 1875 pelo dr. Benjamin Ward Richardson. No século XIX cidades como Londres, Paris, Berlim e Nova Tork tiveram a "City of Dreadful Night", caracterizada pela fome, má qualidade habitacional, falta de higiene, pobreza e trabalho infantil, muito em decorrência do excesso de imigrantes. Essa situação gerou inúmeras revoltas. Com o aumento da urbanização e deterioração das condições de vida, ocorreu a degradação da saúde urbana e proliferação de doenças infecciosas. Diversos movimentos cívicos reivindicaram melhorias na salubridade urbana (GASPAR, 2007; SIMÕES, 2007).

A cada período do desenvolvimento das cidades, correspondeu uma ideia de cidade, uma concepção de sociedade perfeita. Isso pode ser observado de modo particular no urbanismo utópico, com a proposição de tentativas de resposta aos problemas advindos da urbanização acelerada. 


\section{Revista Nacional de}

As primeiras leis urbanísticas relacionadas ao ideário sanitaristas surgiram na Inglaterra, em 1832, seguida de Paris, com legislação de 1850, com consequentes intervenções drásticas no tecido urbano, levadas a termo por Georges-Eugène Haussmann (Figura 1). No Brasil como reflexo deste pensamento, temos a reforma urbana no Rio de Janeiro (Figura 2), desenvolvida por Pereira Passos, entre os anos de 1902 e 1906.

Figura 1 - Esquema dos trabalhos de Haussmann em Paris, as linhas mais grossas indicam as novas ruas abertas no tecido urbano

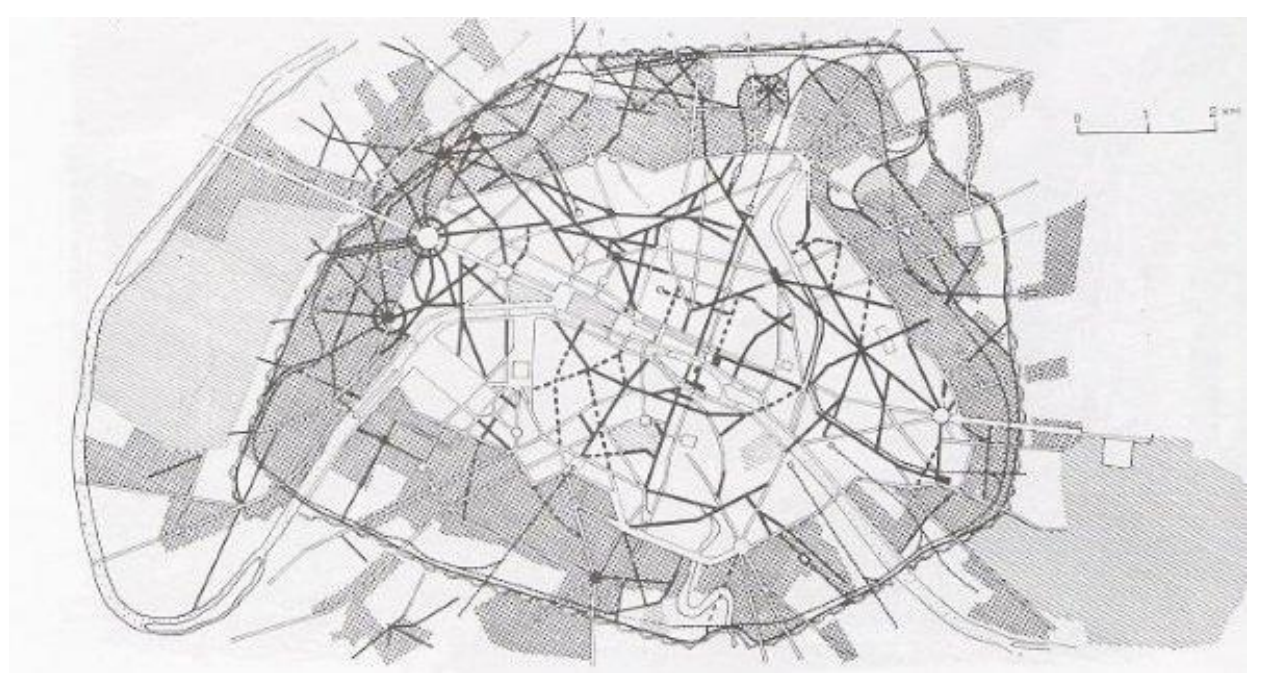

Fonte: BENEVOLO, 1993 


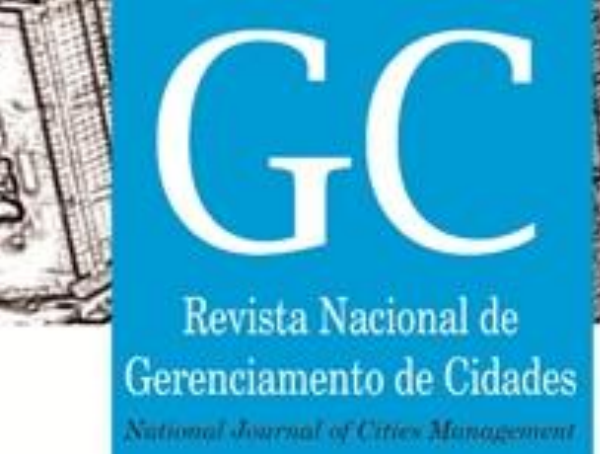

saudáveis. Essas ideias materializaram-se em projetos utópicos como o movimento das cidades jardins, de Ebenezer Howard (Figura 3).

Figura 3: Esquema proposto por Ebenezer Howard para explicar as forças magnéticas de atração nas cidades jardins e a conexão com um cinturão verde essencial para a proposta
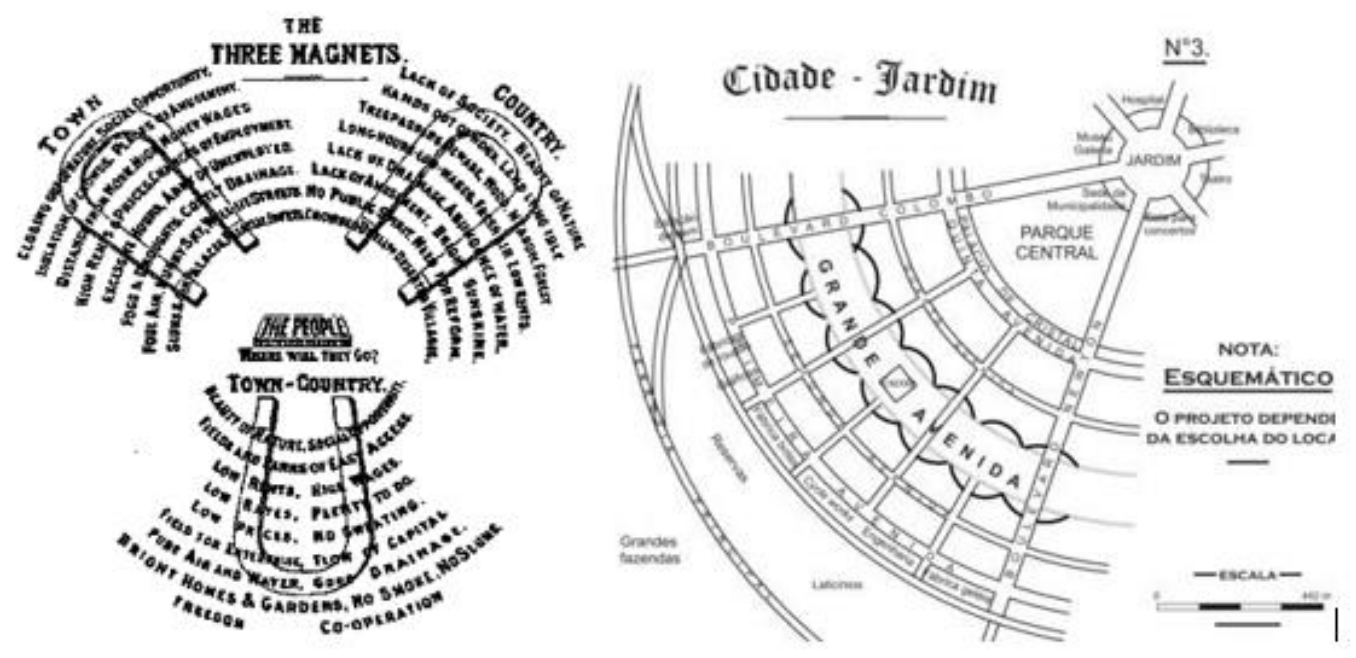

Fonte: BENEVOLO, 1993

Nas primeiras décadas do século $\mathrm{XX}, \mathrm{O}$ arquiteto Le Corbusier concebeu a Ville Contemporaine e a Ville Radieuse (Figura 4), modelos de cidades modernistas altamente controladas, com baixa ocupação do solo urbano, rigidez formal e fixidez funcional. Esta cidade funcionalista, com traçado regular, foi confirmar nos CIAM (Congressos Internacionais da Arquitetura Moderna) e na carta de Atenas, convertendo-se nos mandamentos do urbanismo modernista, Brasília projetada por Lúcio Costa no Brasil e Chandigarh, na Índia, por Le Corbusier, são modelos ímpares dessa ideologia colocada em prática (Figura 5).

\section{CIDADES SUSTENTÁVEIS, CIDADES SAUDÁVEIS}

Mais que um conceito, cidades saudáveis é uma estratégia de promoção da saúde cujo objetivo é a melhoria da qualidade de vida da população. Para uma vida com qualidade são necessários: condições mínimas de existência, acesso a certos bens e serviços econômicos e sociais (emprego e renda, educação básica, alimentação adequada) e acesso a bons serviços de saúde, saneamento básico, habitação, transporte de qualidade etc. 
Figura 4: Ville Contemporaine e Ville Radieuse, propostas de Le Corbusier para a cidade moderna, altamente verticalizada, com liberação do solo urbano e integração com parques urbanos
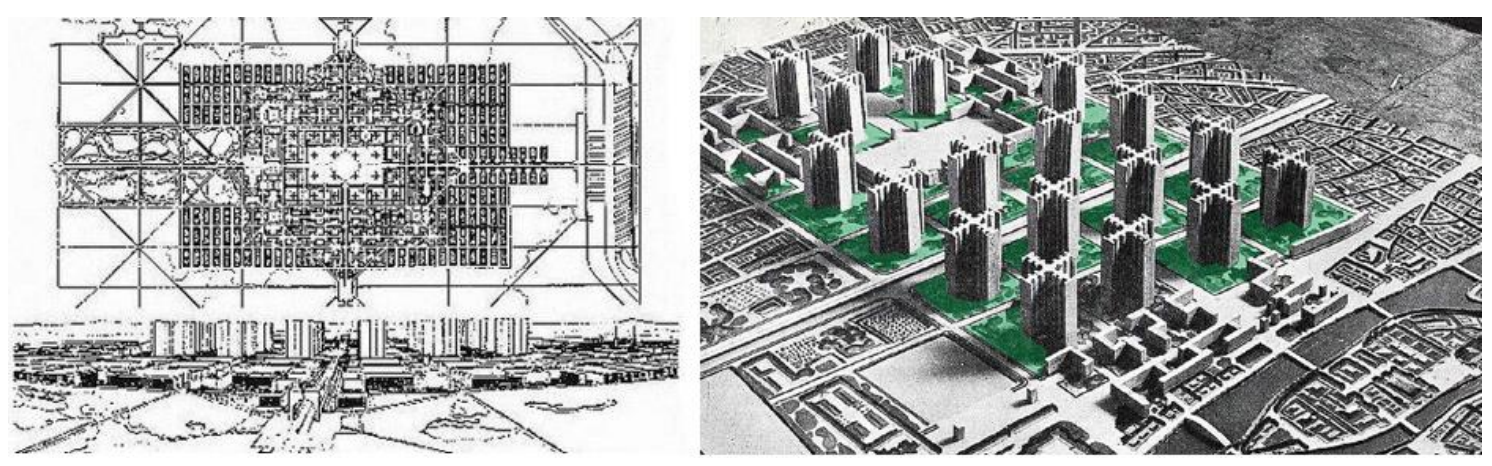

Fonte: PROYECTOS4ETSA, 2018

Figura 5: Planos urbanísticos de Brasília/Brasil e Chandigarh/Índia, exemplos colocados em prática dos ideais modernistas para cidades
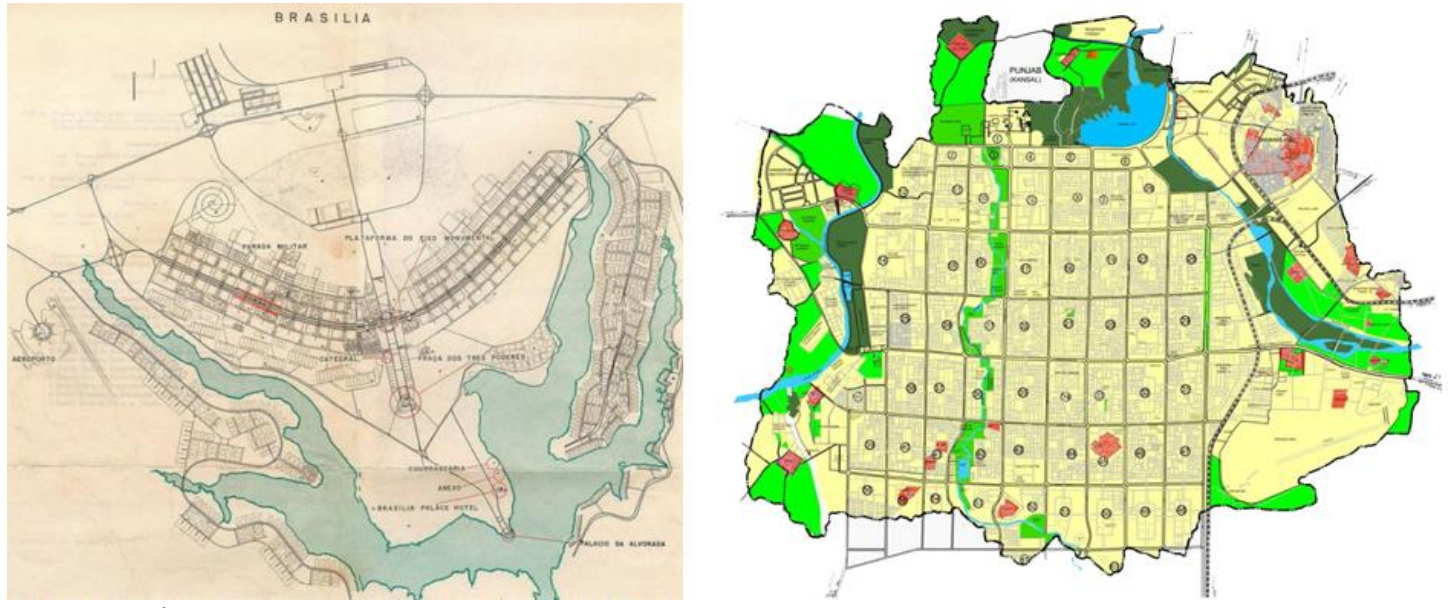

Fonte: SANT'ANNA, 2018 e CULTURENORTHINDIA.COM, 2018

O conceito de cidades saudáveis compreende a cidade como uma estrutura geográfica na qual se vive e trabalha, entendida como unidade administrativa. Neste território diferentes sistemas interagem em busca de um equilíbrio, em meio a relações e conflitos de poder. As cidades assumem papel de atores sociais, convertida em espaço simbólico com objetivos econômicos, políticos e culturais próprios de cada época. Este movimento luta por um estilo de desenvolvimento sustentável, ligado ao ideário da Nova Saúde Pública, ou da produção social da saúde. O objetivo estratégico é motivar governos e sociedades para a melhoria das condições de vida e de saúde das 
populações urbanas, transformando relações excludentes e conciliando interesses econômicos com o bem-estar social. Exige-se um forte caráter de participação social, mobilização e democratização, buscando mudanças na forma de gerir os diferentes níveis de gestão, especialmente o local (WESTPHAL, 2000).

Os municípios que buscam ser saudáveis devem ter seus poderes executivo e legislativo unidos na adoção de políticas públicas integradas que buscam solucionar os problemas diagnosticados, sempre de forma integrada e intersetorial.

Para que uma cidade se torne saudável deve esforçar-se para proporcionar: um ambiente físico limpo e seguro; um ecossistema estável e sustentável; alto suporte social, sem exploração; alto grau de participação social; necessidades básicas satisfeitas; acesso a experiências, recursos, contatos, interações e comunicações; economia local diversificada e inovativa; orgulho e respeito pela herança biológica e cultural; serviços de saúde acessíveis a todos e um alto nível de saúde (ADRIANO et al, 2000).

No entanto, dizer que o objetivo do planejamento urbano deve visar a qualidade de vida dos cidadãos pode ser uma banalidade vazia, não permitindo nenhuma proposta concreta de intervenção. Adotar um projeto desta envergadura significa assumir uma política que envolverá de forma global os diferentes setores, ou seja, educação, saneamento, mobilidade etc, o que implica a adoção de transformações radicais nos processos de gestão (LEFEVRE e LEFEVRE, 2004). Tal intenção deve constar também do Plano Diretor e demais normativas de gestão urbana particulares, lembrando que mais que uma política de governo, deve ser uma política de estado, garantida e gerida para além de administrações particulares.

"Cidades Saudáveis" é um movimento global, organizado pela Organização Mundial da Saúde, tendo íntima relação com projetos de cidades sustentáveis da Comissão Europeia, pois abrem a saúde para fatores externos de outros setores, incorporando as questões de qualidade de vida e saúde nos instrumentos de planejamento e gestão (SIMÕES, 2007).

Embora o termo "qualidade de vida" seja muito banalizado na atualidade, servindo muitas vezes de marketing para empreendimentos imobiliários e apropriado pelo mercado, é de suma importância para o planejamento urbano. Juntamente com o conceito de bem-estar, ponderam um conjunto de variáveis, como emprego, habitação, acesso à educação, saúde e cultura, além das práticas nos tempos livres. 0 acesso à qualidade de via ou bem-estar urbanos dependem do nível social, econômico e cultural, relacionando-se mais às procuras que às ofertas desses serviços (GASPAR, 2007). 
A ideia de qualidade de vida introduz uma valorização de horizontes desejáveis para determinados grupos sociais, com diferentes níveis de exigência e aspirações. 0 conceito guarda relação com a satisfação das necessidades humanas, com a capacidade de uma comunidade desfrutar de uma vida média longa e saudável. Porém, para Vitte (2009), a satisfação dessas necessidades básicas está longe de garantir uma vida com qualidade plena, sendo de suma importâncias fatores relativos à sociabilidade.

De acordo com DeCastro, Saldanha e Balassiano (2017: 208):

A qualidade de vida no espaço urbano está diretamente relacionada à capacidade adaptativa (princípio de resiliência) do ecossistema urbano em responder ao processo de autorregulação para a manutenção de seu equilíbrio dinâmico, ou seja, para manter a sua vitalidade e longo prazo.

\section{CONSIDERAÇÕES FINAIS}

A construção de cidades mais sustentáveis e saudáveis pressupõe uma vontade política e engajamento de toda comunidade, com objetivo de melhorar a qualidade de vida. A saúde, entendida em sua positividade, deve ser garantida por políticas públicas intersetoriais e integrais. O planejamento urbano ao adotar como foco a qualidade de vida e a criação de ambientes saudáveis, deverá articular todas as forças em jogo no cenário urbano para garantir que além das necessidades básicas, a população também tenha acesso a outras necessidades, como segurança ambiental, pertencimento e sociabilidade, reconhecimento e autonomização.

A cidade é composta por diversos ambientes e espaços, sendo o espaço público urbano o local privilegiado de encontro e relação social. São estes espaços que devem garantir a vitalidade urbana, pois se estes estiverem saudáveis e sustentáveis, as pessoas terão uma percepção mais positiva da vida urbana, conformando assim cidades mais saudáveis, resilientes e sustentáveis.

\section{REFERÊNCIAS BIBLIOGRÁFICAS}

ADRIANO, J. R.; et al. A construção de cidades saudáveis: uma estratégia viável para a melhoria da qualidade de vida? Ciência \& Saúde Coletiva, 5(1): 53-62, 2000.

AKEMAN, Marco; DUHL, Leonardo; BOGUS, Cláudia Maria. A questão urbana e a saúde: impactos e respostas necessárias. In CASTRO, Adriana. SUS: ressignificando a promoção da saúde. São Paulo: Hucitec, 2006. 


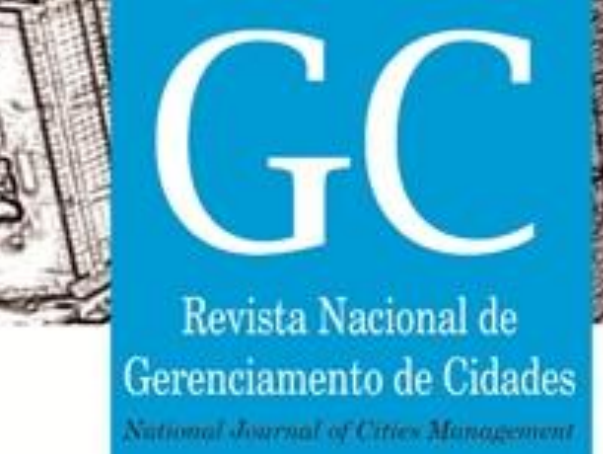

ISSN 2318-8472

v. 06, n. 38,2018

AROUCA, Sérgio. O dilema preventivista: contribuição para a compreensão e crítica da Medicina Preventiva. São Paulo: Editora UNESP; Rio de Janeiro: Editora Fiocruz, 2003.

BONATTO, D. A. M. Qualidade de vida urbana e participação social: a experiência da Rede de Comunidades Saudáveis do Estado do Rio de Janeiro. Tese (Doutorado). Rio de Janeiro: UFRJ, 2012.

BONETI, L. w. Políticas públicas por dentro. 2. ed. Ijuí: Editora Unijuí, 2007.

BUSS, Paulo Marchiori. Promoção da saúde e qualidade de vida. Ciência \& Saúde Coletiva, 5 (1): 163-177, 2000.

BUSS, Paulo Marchiori. Uma introdução ao conceito de Promoção da Saúde. In: CZERESNIA, Dina; FREITAS, Carlos Machado de. Promoção da saúde: conceitos, reflexões, tendências. Rio de Janeiro: Editora Fiocruz, 2009.

CANCLINI, Garcia Néstor. Culturas Híbridas: estratégias para entrar e sair da modernidade. 4. ed. São Paulo: Editora da USP, 2013.

CARTA DE OTAWA. Primeira Conferência Internacional sobre Promoção da Saúde, 1986. In: BRASIL, Ministério da Saúde. As cartas da Promoção da Saúde. Brasília: Ministério da Saúde, 2002.

CASTELLS, Manuel. A questão urbana. Rio de Janeiro: Paz e Terra, 1983.

CASTELLS, Maneul. Cidade, democracia e socialismo. Rio de Janeiro: Paz e Terra, 1980.

CZERESNIA, Dina; FREITAS, Carlos Machado de. Promoção da saúde: conceitos, reflexões, tendências. Rio de Janeiro: Editora Fiocruz, 2009.

DECASTRO, Juliana; SALDANHA, Luiz; BALASSIANO, Ronaldo. Caminhabilidade: expressão do metabolismo urbano. In: ANDRADE, Victor; LINKE, Clarisse Cunha. Cidades de pedestres: a caminhabilidade no Brasil e no mundo. Rio de Janeiro: Babilonia Cultura Editorial, 2017.

FERREIRA, José Roberto. Prefácio. In: RABELLO, Lucíola Santos. Promoção da saúde: a construção social de um conceito em perspectiva comparada. Rio de Janeiro: Editora Fiocruz, 2010.

GASPAR, Jorge. Cidade, saúde e urbanização: apontamentos e notas de leitura. In: SANTANA, Paula. A cidade e a Saúde. Coimbra: Gráfica de Coimbra, 2007.

GUATTARI, Félix; ROLNIK, Suely. Micropolítica: cartografias do desejo. 6 ed. Petrópolis: Vozes, 2000.

LEFEBVRE, Henri. $O$ direito à cidade. São Paulo: Centauro, 2001.

LEFEBVRE, Henri. A revolução urbana. Belo Horizonte: Editora UFMG, 1999.

LEFEVRE. Fernando; LEFEVRE, Ana Maria Cavalcanti. Promoção de saúde: a negação da negação. Rio de Janeiro: Vieira \& Lent, 2004.

LYNCH, Kevin. A boa forma da cidade. Lisboa: Edições 70, 2015.

MACHADO, Maria do Céu Soares. Prefácio. In: SANTANA, Paula. A cidade e a Saúde. Coimbra: Gráfica de Coimbra, 2007.

MENDES, E. V. Uma agenda para a saúde. São Paulo: HUCITEC, 1996.

MUMFORD, Lewis. A cidade na história: suas origens, transformações e perspectivas. 4. ed. São Paulo: Martins Fontes, 1998. 


\section{Revista Nacional de}

PAIM, J. S.; ALMEIDA FILHO, N. A crise da saúde pública e a utopia da saúde coletiva. Salvador: Casa da Qualidade Editora, 2000.

SILVA, F. F. A. Novas subjetividades subalternas na cidade: cultura, comunicação e espacialidade. Tese (Doutorado). São Paulo: USP, 2011.

SIMÕES, José Manuel. Construindo cidade saudável. In: SANTANA, Paula. A cidade e a Saúde. Coimbra: Gráfica de Coimbra, 2007.

VITTE, Claudete de Castro Silva. A qualidade de vida urbana e sua dimensão subjetiva: uma contribuição ao debate sobre políticas públicas e a cidade. In: VITTE, Claudete de Castro Silva; KEINERT, Tânia Margarete Mezzomo. Qualidade de vida, planejamento e gestão urbana: discussões teórico-metodológicas. Rio de Janeiro: Bertrand Brasil, 2009.

WESTPHAL, Marcia Faria. O movimento cidade/municípios saudáveis: um compromisso com a qualidade de vida. Ciência \& Saúde Coletiva, 5(1): 39-51, 2000.

WESTPHAL, Marcia Faria. Promoção da saúde e prevenção de doenças. In: CAMPOS, Gastão Wagner de Souza; SOUZA, Edinilsa Ramos de. Tratado de Saúde Coletiva. São Paulo: HUCITEC; Rio de Janeiro, Ed. Fiocruz, 2006. 